\title{
ENGAGING MEDICAL AND BIOMEDICAL STUDENTS TOWARDS ETHICS AND ETHICAL CONDUCT VIA CASE STUDY BASED APPROACH: REFLECTIONS FROM AN ONLINE WORKSHOP
}

\author{
Shiva Das Sivasubramaniam, Zeenath Reza Khan
}

\begin{abstract}
Ethics and ethical behaviour form an important part in clinical science and biomedical research. Ethical education should be comprehensively taught aiming to help graduate/undergraduate students to practice by applying underlying principles. Several innovative types of learning strategies are being employed to deliver these sessions. One such method is the "case study based delivery" in which students are presented with a variety of case studies highlighting the issues to create an interactive learning. In this investigation authors wanted to showcase this approach to the Middle-Eastern medical/biomedical students and thereby (a) validate the effectiveness of this case study based delivery and (b) to explore the effectiveness of delivering case study based ethical education in a virtually online environment. In this manuscript, we share our experiences from this session by a narrative commentary of our observation and analysis on student interactions

The study shows that the opportunities for integrated learning and problem solving abilities can be the best solution for learning to apply the appropriate ethical principle in clinical context. Conducting an online interactive session with a large scale of attendees (around 258 participants) can be a challenge which can be tackled by excellent IT support.
\end{abstract}

Key words: Bioethics, Medical ethics, Case Study Approach, Education, Medical Research

\section{Introduction}

Ethics and ethical behaviour form an important part in clinical science and biomedical research. Whilst patient safety, confidentiality and privacy take precedence in clinical medicine; ethically warranted study design, methodologies and data handling is vital for biomedical research. In fact, ethics in medical research deals with the conflicts of interest across various levels. Many treaties and declarations are in place to enforce ethical behaviours, especially in medical research (Gurayaa et al, 2014). As clinicians and researchers have the obligation to follow the ethical principles in their practice, it is imperative to educate young medical students on different dimensions of ethics in medical practice, such as research ethics, and the seriousness of misconducts. It is also essential to teach young scientists about good laboratory and scholarly practice in research (Masic, 2012). Also, more young doctors are getting involved in basic research and scholarly activities outside their usual territory of "clinical/patient based medicine" involving in vitro/animal research, and data handling. Likewise, several basic scientists are carrying out in vivo medical research involving patients.

At the beginning of this decade, the World Medical Association's (WMA, 2015) included ethical education as an obligatory curriculum within medical education. 
Whilst there is a greater emphasis of incorporating ethical education to medical students, it is not clear whether the research scientists are being taught about ethics, ethical behaviour and the consequences on intentional or un-intentional misconducts. On other hand, with the advent of genetic engineering, stem cell therapy, and genomic manipulations, the medical profession itself is facing new ethical challenges. Therefore, teaching bioethics to students with multi-disciplinary focus is imperative. Especially the fact that, the ethical decisions are subject to the situation, local legislations, and may be incorrectly influenced by moral justifications (Safuan et al, 2017). Young scientist/doctors are expected to critically analyse the situation with proper reasoning according to each ethical problems/situations. They need to develop critical thinking based on the information provided, as they become accountable for their own decisions.

Therefore, bioethics should be comprehensively taught aiming to help graduate/undergraduate students to practice by applying underlying principles. Many medical schools and other institutions use traditional lecture based delivery on ethical principles. Whilst it is important for young clinicians/scientists to learn the basic ethical principles, these lecture based delivery is often seen as "boring" and "dry", which is not always linked to day-to-day practice.

Also, the teaching curricula in many universities are fully "saturated" with course specific contents which often makes it difficult to incorporate ethical education into their delivery. Hence some institution run extra sessions to deliver bio/medical ethics (Weatherall, 1995). In fact, it has never been clear how to deliver sessions on ethics and ethical conduct. Therefore, more innovative types of learning strategies are being employed to deliver these sessions. One such method, a "case study based delivery" was employed by the corresponding author in his institution. In this methods, students were presented with a variety of case studies highlighting the issues in biotechnology, clinical medicine, food technology, biomedical science etc. Students were then grouped into two panels to discuss/debate (for and against) each scenario. Finally, the underlying principles were discussed in a plenary session. Although this approach was found to be time consuming ( 3 hour sessions as opposed to one-hour lecture slots), it has generated full attention and engagement amongst the students.

The authors originally wanted to showcase this approach to the Middle-Eastern medical/biomedical students and validate the effectiveness of this case study based delivery with students of cultural background. However, due to Covid-19 pandemic it was impossible to carry out this face-to-face interactive teaching. Yet we transformed this challenge into an opportunity to examine the possibility of delivering this session online but maintain the interactive nature of the session. Thus the modified aim of this investigation is to explore the effectiveness of delivering case study based ethical education in a virtually online environment. In this manuscript, we share our experiences from this session.

\section{Methods}

This workshop was conducted in the Department of Biomedical Sciences, College of Medicine, Gulf Medical University, Ajman in the United Arab Emirates. The session 
was delivered using GoTomeeting ${ }^{\circledR}$ webtool. There were 258 attendees, many of them were medical/biomedical science students with some junior doctors and biomedical scientists. The session was voice recorded and the interactions were anonymously monitored in accordance with the ethical policies of Gulf Medical University for conducting lectures and student activities. The convener (Dr Sivasubramaniam) was visible to the students but his video link to the "class" was disabled to maintain anonymity. Yet students/attendees could still raise questions, discuss and interact with the convener via audio link. Feedback as written comments from the participants on the overall satisfaction of the session were collected at the end of the session

Originally the session was intended to run for two hours, but due to high levels of interaction, it was prolonged for an additional hour (see discussion). Six different real life example case studies used in this session. Their summary together with links to the original stories are given in table 1 . An example case study with related questions to generate discussion/interactions are given below (underneath the table 1)

Table 1

Summary of Case studies used in the session

\begin{tabular}{|c|l|l|}
\hline Case & Short title/Ethical dilemma & Brief description \\
\hline 1 & The right to use the embryo & $\begin{array}{l}\text { Ms Evans Vs United Kingdom - Withdrawal of consent for } \\
\text { using embryos by the former partner (WWW-1) }\end{array}$ \\
\hline 2 & The right to live / Parent's right & $\begin{array}{l}\text { Alfie Evens Vs United Kingdom - Parents fight against } \\
\text { withdrawing life support of a brain dead baby (WWW-2) }\end{array}$ \\
\hline 3 & The right to end life & $\begin{array}{l}\text { Dr David Goodall - Wanted to end his life due to the fear of } \\
\text { losing human dignity related to old age (WWW-3) }\end{array}$ \\
\hline 4 & Patient's right & $\begin{array}{l}\text { Unknown patient with a Do Not Resuscitate (DNR) tattoo } \\
\text { (WWW-4) }\end{array}$ \\
\hline 5 & Informed consent & $\begin{array}{l}\text { Research methodology - HIV vaccine trial using } \\
\text { injecting-drug addicts (WWW-5) - (Smit et al, 2005) }\end{array}$ \\
\hline 6 & Genetic modification & $\begin{array}{l}\text { Genetic engineering - Inserting protein to resist nematode } \\
\text { infection in potatoes (WWW-6) - (Gewin, 2013) }\end{array}$ \\
\hline
\end{tabular}

\section{Observation and analysis on student interactions}

The session started with an initial introduction about the aims of this workshop and followed but a brief overview of the basic principles of medical and bioethics. Then each case study was presented with respective questions for polling. In fact, these questions were generated to create discussion/interactions between the students/attendees and conveyer. An example summary poll of results (for the questions linked to the case study given above) is summarised in figure 2 (see below). Here the data is used to show the engagement, as can be seen on average around $51 \%$ of the students (131 out of 258) attempted to answer the questions within the allowed 3-minute window. As organisers we realised the time window given was not enough for all of them to complete their answers, only when we received comments such as "the duration for poll is not enough" and "the poll closed before I completed my response" in the interactive comments window. 


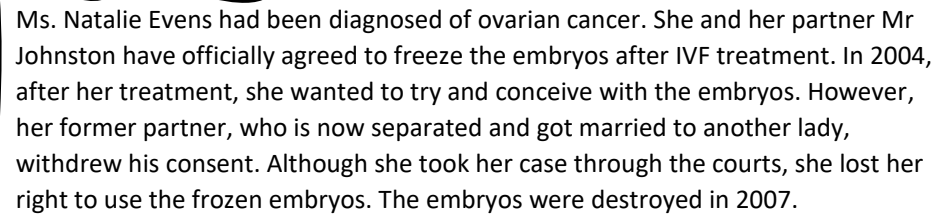

1. Is Johnston's decision to withdraw consent justifiable?
(a) Yes
(b) No

2. Does the court's decision to destroy the embryos justifiable?
(a) Yes
(b) No

3. What other alternate ways/actions Natalie would have taken?

(a) Must have frozen her ova (eggs) instead of embryo

(b) Secretly implant the embryo in another country

Figure 1. An Example Case study with questions for discussion

The figure 2 shows an indication of percentage student engagements. On average 131 students/attendees (out of 258 ) (i.e. $51 \%$ ) to all three questions related to the case study 1 (see an example case study given above)

Likewise, the GoTomeeting ${ }^{\circledR}$ webtool generated data, based on clicks, responses (both written and oral), and feedback suggested that the "total average attentiveness" was 82.75 out of 100 in arbitrary units. Although this does not necessarily reflect the participant engagement, it can be said the session created an interactive dialogue between the participants and the convener. In addition, there were a lot of questions, comments (both oral and written) in the interactive comments window. We originally allocated 20 minutes for discussing each case study, however due to the high demand and interactions, we were forced to increase the allocation to 30 minutes per case study. Interestingly, the interactions did show that the participants were thinking outside the box as real life ethical dilemmas are more complicated than the text book definitions. In fact, the participant has realised that in real life the day-to-day decision making the focus should on "how" to approach the situation in hand (rather than what ethical principle to apply). The interaction clearly shown that the participant has understood the practical application of ethical principles in medicine and research depends on them (or the front line staff). There were several example conversations to show this. During discussions about case study 1, one participant asked a question " $D r X X X X$ ! Isn't it justifiable for Johnston to be forced to financially and emotionally support a child he doesn't want". This question itself shows that the participant is considering the wellbeing of all parties involved (and not just the obvious victim). Another student stated "I love that you chose this case scenario. Myself and a friend actually discussed this specific case before and we couldn't really decide". This again shows that they 


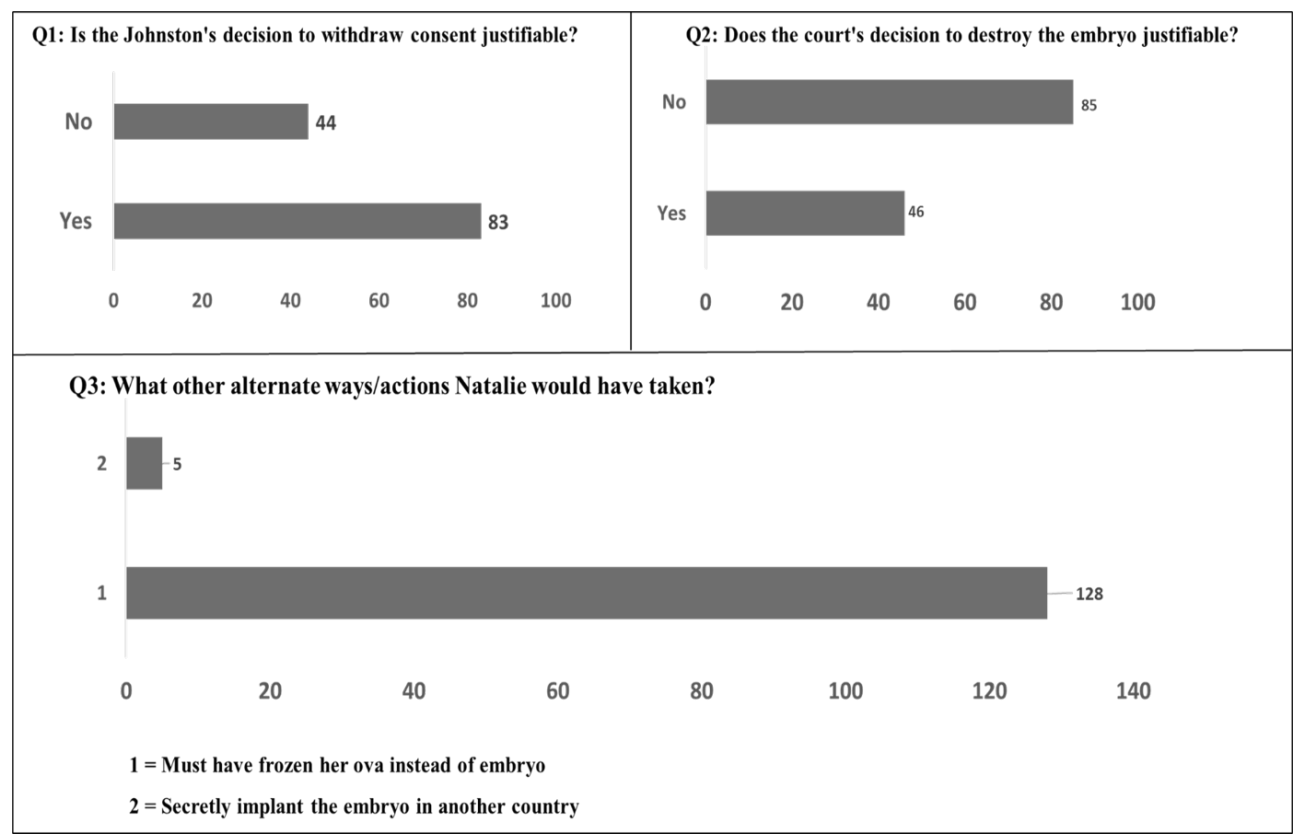

Figure 2. Example responses for the case study one to show average online engagement

have understood the ambiguous nature of real life situation. Likewise, in case study 2 about Alfie's case (parents right to decide on the fate of keeping this child alive), one participant correctly pointed out "in a scenario where there is a conflict between the parents and the hospital, the decision should be with the courts. They would have the best interests of the child at hand". This shows he/she have clearly weighed the pros and cons of "the parent's right to decide" and put forward the most practicable solution. Another participant thought laterally beyond the scenario and correctly stated "leaving the parents (solely) with the right to decide would have huge implications in a child abuse case". Similarly, during discussions of case study 4 (patient's right to decide) about an unknown patient with "Do not resuscitate (DNR)" tattoo, one participant asked "do you think a different decision would have been taken in a country where the law states that DNR is unacceptable?" This proves that the participants are thinking of real life applications by relating these case studies to their day-to-day practice. This is an indication of maximum engagement with the session.

At the end of the session some students sincerely thanked the organisers and requested to similar webinar's to be held in the future. As for where the anonymous written feedback is concerned there were several positive comments from the participants. Table 2 summarises the important comments received, it was promising to note several commendations from the students and the conference attendees. On the negative side, there were only a few points raised, most of them are highlighting the issues with the online platform. 
Table 2

Summary of anonymous feedback comments from the participants

\begin{tabular}{|c|c|}
\hline Positive comments & Negative comments \\
\hline "Really interesting. Thank you!" & $\begin{array}{l}\text { "Only one concern! Each question shall be projected } \\
\text { for } 3 \text { mins instead of } 2 \text { mins" }\end{array}$ \\
\hline $\begin{array}{l}\text { "Value for attending this session is striking; we all } \\
\text { are enjoying" }\end{array}$ & $\begin{array}{l}\text { "Biomedical science student here; others attending } \\
\text { as well - Can you include more biomedical case } \\
\text { studies too" }\end{array}$ \\
\hline "Your questions are making us think a lot." & $\begin{array}{l}\text { "Unfortunately often ethical decisions kill our moral } \\
\text { values... Is it right?" }\end{array}$ \\
\hline "You are an amazing teacher, a lot to learn from you" & "We could not see some of the questions" \\
\hline $\begin{array}{l}\text { "An excellent session and to keep us thinking all the } \\
\text { time" }\end{array}$ & "The duration for poll is not enough" \\
\hline $\begin{array}{l}\text { "It is very interesting! Trust we will have more } \\
\text { session with you..." }\end{array}$ & "The poll closed before I completed my response" \\
\hline "It has been an amazing session thank you doctor" & \\
\hline $\begin{array}{l}\text { "This was a very enlightening lecture on ethics really } \\
\text { gained a lot. Thank you Dr" }\end{array}$ & \\
\hline $\begin{array}{l}\text { "Bravo for this post-conference session offer for the } \\
\text { PAEB2020 delegates too!" }\end{array}$ & \\
\hline $\begin{array}{l}\text { "Excellent Post Conference Workshop. Stay safe and } \\
\text { Take care" }\end{array}$ & \\
\hline
\end{tabular}

With the perception of the sessions being delivered in a medical school, we have included more medical ethics cases with minimal (only one) relating to biotechnology related case study (case study 6). This was highlighted by the biomedical science students who insisted on receiving similar workshops with biomedical science related case studies in future. Also there was a one general comment regarding the conflict between "ethical decision" and "moral values" which was handled within the session and full explanation given. The other two were related to the online platform and the fact that there was less time provided to attempt all the questions.

\section{Concluding remarks}

Medical ethics and bioethics are broad, and interdisciplinary fields which encompass many controversial matters. Likewise, teaching ethics involves practical applications which might change depending on clinical or research situation. Therefore, many universities are adopting innovative teaching methodologies. The concept of these innovative techniques of teaching was first put forward by Ronald Harden in 1984 (see also Harden and Laidlaw, 2012) and named as SPICES model (the acronym SPICES stands for student-centred learning, problem-based learning, integrated/interprofessional teaching, community based education, elective studies, and a systematic approach). In this context, some of the medical/biomedical schools started including short stories, novels, plays, and films as a part of the bioethics education. These materials present case examples that would highlight practical problems in a clinical and/or research set up (Robeson and King, 2017; Dent, 2014). Thus, case-based approaches to teaching medical ethics have a long tradition in medical education. 
As a part of European Network Academic Integrity (ENAI) strategy, we have been delivering similar workshops to medical/biomedical students in different countries around Europe and beyond since 2016. However, this is the first occasion in which the workshop was delivered entirely online. Therefore, we wanted to measure the effectiveness of the online delivery of case study based approach (which needs student interactions). We wanted to know whether a large scale workshop can be delivered with maximum student interactions. As explained in the narrative observational analysis above, despite the fact that the session was delivered online, the participants have shown a keen interest in the discussions of each case studies. Conducting an online interactive session with a large scale of attendees (around 258 participants, all at different places/venues) was a challenge. This was tackled by the excellent IT support received from the organisers (see acknowledgements). Above all, the data shows that the opportunities for integrated learning and problem solving abilities can be the best solution for learning to apply the appropriate ethical principle in clinical context.

\section{Acknowledgements}

The authors wish to thank Dr. Gomathi Kadayam Guruswami, the head of biomedical science department and Mr. Suraj Sebastian, the senior IT technician at College of Medicine, Gulf Medical University, Rashid Al-Khadar Street, Al Jerf 1, Ajman - United Arab Emirates for organising and providing excellent IT support respectively.

\section{References:}

Aguilera, M. L., Martínez Siekavizza, S., \& Barchi, F. (2019). A Practical Approach to Clinical Ethics Education for Undergraduate Medical Students: A Case Study From Guatemala. J Med Educ Curric Dev. doi:10.1177/2382120519869207

DENT, J. (2014). Using the SPICES model to develop innovative teaching opportunities in ambulatory care venues. Korean Journal of Medical Education. 26(1):3-7. www.doi:https://doi.org/10.3946/kjme.2014.26.1.3

GEwIN, V. (2013). Genetically modified corn-environmental benefits and risks. PLoS Biol. 1(1):E8. doi:10.1371/journal.pbio.oooooo8

GurayaA, S. Y., London, N. J. M., GurayaA, S. S. (2014). Ethics in medical research Journal of Microscopy and Ultrastructure. 2(3): 121-126 https://doi.org/10.1016/j.jmau.2014.03.003

HARDEN, R. M., \& LAIDLAW, J. M. (2012). Essential skills for a medical teacher: an introduction to teaching and learning in medicine. Edinburgh, UK: Churchill Livingstone; 2012.

Harden, R. M., Sowden, S., \& Dunn, W. R. (1984). ASME Medical Education Research Booklet No. 18. The SPICES Model. Med Educ 18:284-297

MAsIC, I. (2012). Ethical aspects and dilemmas of preparing, writing and publishing of the scientific papers in the biomedical journals. Acta Inform Med. 20:141-8.

Robeson, R., \& King, N. M. P. (2017). Performable Case Studies in Ethics Education. Healthcare (Basel). 5(3):57. www.doi:10.3390/healthcare5030057

Safuan, S., Ali, S. H., KuAn, G., Long, I., Norliza, N., \& Hassan, N. (2017). The Challenges of Bioethics Teaching to Mixed-Ability Classes of Health Sciences Students. Education in Medicine Journal. 9(4): $41-49$ 
Smit, J., Middelkoop, K., Myer, L., Lindegger, G., Swartz, L., Seedat, S., Tucker, T., Wood, R., Bekker, L. G., \& STEIN, D. J. (2005). Socio-behaviour challenges to phase III HIV vaccine trials in Sub-Saharan Africa. Afr Health Sci. 5(3):198206. doi:10.5555/afhs.2005·5·3.198

WeAtherall, D. J. (1995). Guest editorial Teaching ethics to medical students Journal of medical ethics. 21: 133-134 http://dx.doi.org/10.1136/jme.21.3.133

WMA. (2015). https://www. wma.net/policies-post/wma-resolution-on-the-inclusion- of -medical-ethics-and-human-rights-in-the-curriculum-of-medical-schools-world-wide/

\section{Links for case studies:}

WWW1

https://www. theguardian.com/society/2007/apr/11/health.medicineandhealth1

WWW2

https://www.bbc.co.uk/news/uk-england-merseyside-43754949

$\mathrm{WWW}_{3}$

https://www.abc.net.au/news/2018-05-10/david-goodall-ends-life-in-a

- powerful-statement-on-euthanasia/9742528

$\mathrm{WWW}_{4}$

https://www. washingtonpost.com/news/to-your-health/wp/2017/12/o1/a-man

- collapsed-with-do-not-resuscitate-tattooed-on-his-chest-doctors-didnt

-know-what-to-do/

$\mathrm{WWW}_{5}$

https://www.ncbi.nlm.nih.gov/pmc/articles/PMC1831933/

WWW6

https://www.ncbi.nlm.nih.gov/pmc/articles/PMC212689/

\section{Authors}

Shiva Das Sivasubramaniam, University of Derby, Kidleston Road, DE22 1GB Derby, United Kingdom, e-mail: S.Sivasubramaniam@derby.ac.uk

Dr Zeenath Reza Khan, University of Wollongong in Dubai, Knowledge Park, 20183 Dubai, United Arab Emirates, e-mail: zeenath.khan@gmail.com 